Gynecology

\title{
Healthcare provider attitudes regarding the provision of assisted reproductive services for HIV-affected couples in Addis Ababa, Ethiopia
}

\author{
Alana N. Pinsky ${ }^{1, \dagger}$ | Kylie Steenbergh ${ }^{1}$ | Heather M. Boyd ${ }^{2, \dagger} \mid$ \\ Belen Michael $^{2, \dagger}$ | Delayehu Bekele ${ }^{3}$ | Emily Kobernik ${ }^{4}$ | \\ Lia Tadesse Gebremedhin ${ }^{1,3, \dagger}$ | Okeoma Mmeje ${ }^{1,2,4, *}$
}

\author{
${ }^{1}$ University of Michigan Medical School, \\ Ann Arbor, MI, USA \\ ${ }^{2}$ University of Michigan School of Public \\ Health, Ann Arbor, MI, USA \\ ${ }^{3}$ St. Paul's Hospital and Millennium Medical \\ College, Addis Ababa, Ethiopia \\ ${ }^{4}$ Department of Obstetrics and Gynecology, \\ University of Michigan, Ann Arbor, MI, USA

\section{${ }^{*}$ Correspondence} \\ Okeoma Mmeje, L4100 Women's Hospital, \\ 1500 East Medical Center Drive, Ann Arbor, \\ MI 48109, USA. \\ Email: ommeje@med.umich.edu \\ ${ }^{\dagger}$ Affiliation at the time of the study.
}

Funding Information

African Studies Center; Institute for Research on Women and Gender; Department of Obstetrics and Gynecology

\begin{abstract}
Objective: To evaluate the acceptability and feasibility of providing assisted reproductive services as part of routine HIV care and treatment in Ethiopia.

Methods: The present cross-sectional study using semistructured in-depth interviews was conducted at St. Paul Hospital Millennium Medical College (SPHMMC), Addis Ababa, Ethiopia, during July 2014 and July 2015. The interviews assessed the perspectives of healthcare providers (HCPs) regarding the reproductive desires of HIVaffected couples, on assisting them in achieving pregnancy, and on the facilitators and barriers to offering such services as part of routine HIV care.

Results: There were $40 \mathrm{HCPs}$ from two SPHMMC clinics interviewed. All HCPs asserted that HIV-affected couples should have equal access to assisted reproductive services and most agreed that couples should have this access to reduce the risk of HIV transmission, even in the absence of underlying infertility. However, the HCPs cited systemic and structural barriers to the implementation and delivery of assisted reproductive services. Conclusion: The integration of assisted reproductive services into HIV care and treatment programs is acceptable and feasible to HCPs. Formal training of HCPs may improve the implementation of these services for HIV-affected couples in lowresource settings.
\end{abstract}

KEYWORDS

Ethiopia; Healthcare provider; HIV; HIV-affected couples; Pregnancy; Reproduction; Safer conception; Sub-Saharan Africa

\section{1 | INTRODUCTION}

Infection with HIV remains a prevalent condition on the African continent, particularly in urban areas. In Ethiopia, estimates of HIV prevalence are $2.9 \%$ among women and $1.9 \%$ among men. ${ }^{1}$ Advances in the availability and provision of antiretroviral therapy have translated into substantial reductions in HIV-associated morbidity and mortality. ${ }^{2}$ Individuals infected with HIV can live long and full lives, which includes fulfilling their reproductive goals and desires. In Ethiopia, there are strong cultural and personal pressures to reproduce, and many HIV-affected couples wish to have children. ${ }^{3}$ A 2014 study ${ }^{4}$ found that $44 \%$ of HIV-infected women of childbearing age in Addis Ababa, Ethiopia, desired children in the future.

In HIV-affected couples, condomless sexual intercourse may be associated with HIV transmission when HIV viral suppression in the infected partner is not assured. Therefore, HIV treatment 
and prevention efforts should be focused on HIV-serodiscordant couples (where one partner is HIV-infected whereas the other is HIV-uninfected), particularly those who are attempting to achieve pregnancy. It is estimated that $44 \%$ of couples in Sub-Saharan Africa are HIV-serodiscordant, and that sexual HIV transmission within serodiscordant relationships may account for more than $60 \%$ of new HIV infections. ${ }^{5}$ In partnerships that are HIV-serodiscordant in which pregnancy occurs, the risk of HIV acquisition for the uninfected partner is nearly double that of partnerships in which pregnancy does not occur. ${ }^{6}$ This risk represents a deterrent to some HIV-affected couples planning to have children. ${ }^{7}$

Assisted reproductive services (intrauterine insemination when the female partner is HIV-infected; sperm washing with intrauterine insemination if the male partner is HIV-infected; and timed condomless intercourse with or without HIV preexposure prophylaxis) are intended to reduce the risk of HIV transmission during attempts at achieving pregnancy in HIV-serodiscordant couples. ${ }^{8}$ Despite the simplicity and cost of several of these methods and their availability in resource-rich settings, such reproductive options have yet to be introduced to or evaluated in low-resource environments such as Ethiopia. This is particularly paradoxical because low-resource environments tend to have the highest prevalence of HIV in a predominantly reproductive-aged population.

The provision of assisted reproductive services for HIV-affected couples planning to achieve pregnancy should be a priority for healthcare providers (HCPs) providing HIV care and treatment services. The availability and provision of reproductive services for these couples may hold the promise of decreasing the risk of HIV transmission while empowering and supporting HIV-affected couples in their desire to fulfill their reproductive goals.

The objective of the present study was to assess the acceptability and feasibility among HCPs of implementing assisted reproductive services at St. Paul Hospital Millennium Medical College (SPHMMC), one of two major public hospitals in Addis Ababa, Ethiopia. Ultimately, the study aimed to define the facilitators and barriers to providing assisted reproductive services for HIV-affected couples as part of routine HIV care and treatment at a public hospital in Ethiopia.

\section{2 | MATERIALS AND METHODS}

The present cross-sectional study was conducted at SPHMMC-an urban teaching hospital that provides reproductive health services to individuals from the capital Addis Ababa and the neighboring Oromia region of Ethiopia-during two separate months (July 1-31, 2014, and July 1-31, 2015). Study participants were HCPs selected from the hospital's Department of Obstetrics and Gynecology and its HIV Care and Treatment Clinic. The following HCPs were eligible for enrollment: attending staff and second- and third-year residents from the Department of Obstetrics and Gynecology; and health officers, nurses, and counselors from the HIV Care and Treatment Clinic. First-year residents were excluded because of their lack of clinical experience; all other available HCPs were invited to participate in the study. To ensure anonymity, HCPs were de-identified using a study identification number. Participation was voluntary, and written informed consent was obtained prior to the interviews. Ethical approval for the study was provided by the institutional review boards at the University of Michigan, Ann Arbor, MI, USA, and SPHMMC.

Semistructured in-depth interviews using open-ended questions were conducted by two trained interviewers. The interviews assessed $\mathrm{HCP}$ attitudes on the reproductive desires of HIV-affected couples, their personal attitudes on assisting HIV-affected couples in achieving pregnancy, and their assessment of how the sociocultural environment of Ethiopia would be responsive to the introduction of assisted reproductive services for HIV-affected couples. The interviews with obstetrics and gynecology staff physicians (full-time faculty) and residents (physicians in training) were conducted in English, whereas the interviews with HIV clinic staff were conducted in Amharic at the request of the study participants.

The interviews were transcribed and analyzed with Dedoose version 7.0.23 (SocioCultural Research Consultants, Los Angeles, CA, USA) using a grounded theory approach. Four independent investigators (ANP, KS, HMB, and OM) collaborated to develop the codebook and data dictionary, which were finalized after the four investigators independently coded randomly selected interviews and reached consensus. To ensure coding accuracy, a random selection of interviews were double-coded by two investigators (HMB and OM). A thematic analysis was then employed to code the transcribed interviews. The responses were grouped into two major categories: systemic and structural facilitators and barriers.

Quantitative data were obtained from each participant via a questionnaire prior to initiation of the interviews. The survey was designed to take approximately 10 minutes and included 24 questions of the following subtypes: multiple choice, yes or no, five-point Likert scale items (strongly agree to strongly disagree), and free response. The questionnaire addressed HCPs' training, experience, and beliefs regarding the provision of assisted reproductive services to HIV-affected couples planning to achieve pregnancy. Likert scale and multiple choice items assessed HCP beliefs on access to assisted reproductive services for HIV-affected couples and their experience referring these couples to such services.

The demographic and survey data were analyzed using SPSS version 19 (IBM, Amonk, NY, USA). The $\chi^{2}$ or Fisher exact test was used for comparisons of categorical data, where appropriate. $P<0.05$ was considered statistically significant.

\section{3 | RESULTS}

In total, 26 of 31 obstetrics and gynecology staff physicians and second- and third-year residents in obstetrics and gynecology participated in the study, as did 14 of the 15 HCPs from the HIV Care and Treatment Clinic (Table 1).

All HCPs believed that HIV-affected couples should have similar access to assisted reproductive services as HIV-unaffected couples 
TAB LE 1 Study participants at St. Paul Hospital Millennium Medical College, Addis Ababa, Ethiopia $(n=40){ }^{\text {a }}$

\begin{tabular}{|c|c|}
\hline Characteristic & No. (\%) \\
\hline \multicolumn{2}{|l|}{ Department } \\
\hline Obstetrics/Gynecology & $26(65)$ \\
\hline HIV Care and Treatment Clinic & $14(35)$ \\
\hline \multicolumn{2}{|l|}{ Sex } \\
\hline Male & $25(63)$ \\
\hline Female & $15(38)$ \\
\hline \multicolumn{2}{|l|}{ Age, y } \\
\hline $25-30$ & $20(50)$ \\
\hline $31-40$ & $10(25)$ \\
\hline $41-60$ & $10(25)$ \\
\hline \multicolumn{2}{|l|}{ Position } \\
\hline Attending & $8(20)$ \\
\hline Resident & $19(48)$ \\
\hline Health officer & $4(10)$ \\
\hline Nurse & $6(15)$ \\
\hline Counselor & $3(8)$ \\
\hline \multicolumn{2}{|l|}{ Time in position, $y$} \\
\hline $0-4$ & $27(68)$ \\
\hline $5-10$ & $12(30)$ \\
\hline$>10$ & $1(3)$ \\
\hline \multicolumn{2}{|c|}{ No. of patients seen by HCP in clinic/wk } \\
\hline$\leq 10$ & $2(5)$ \\
\hline $11-30$ & $12(30)$ \\
\hline $31-50$ & $3(8)$ \\
\hline $51-70$ & $8(20)$ \\
\hline$>70$ & 15 (38) \\
\hline
\end{tabular}

Abbreviation: $\mathrm{HCP}$, healthcare provider.

as a means of HIV prevention, even without underlying infertility. However, the provision of assisted reproductive services differed significantly between the clinics $(P=0.016)$, as did the frequency of requests for services ( $P=0.003$ ) (Fig. 1). Among the HCPs in the Obstetrics and Gynecology Department, a larger proportion of staff physicians have provided assisted reproductive services compared with residents ( $P=0.028$ ) (Fig. 2 ).

The HCPs in the two clinics identified many similar facilitators and barriers to the uptake and implementation of assisted reproductive services. They noted the following facilitators: childbearing as a right for all, little fear of HIV transmission to an HCP, empowerment of women, and positive attitude toward having a healthy pregnancy (Table 2). However, the HCPs also noted the following as barriers to the uptake and implementation of assisted reproductive services: clinical volume of clients, involvement of male partners, travel for services, and cost of assisted reproductive services (Table 3).

The HCPs in the HIV Care and Treatment Clinic viewed travel to the clinic and the number of available facilities as the greatest barriers to service implementation. These providers also felt that HIV-affected individuals and couples would be more comfortable discussing their reproductive desires and their need for assisted reproductive services with them instead of with HCPs in the Department of Obstetrics and Gynecology. By contrast, the obstetricians and gynecologists identified HIV-related stigma as the greatest barrier. Furthermore, HCPs perceived that there could be generalized fear of the potential for errors, with use of the incorrect sperm with assisted reproductive services.

Knowledge about assisted reproductive services at SPHMMC varied. A greater proportion of staff physicians in obstetrics and gynecology knew that SPHMMC offers some forms of assisted reproductive services, compared with residents (6/7 [86\%] vs 6/19 [32\%], $P=0.021$ ). In addition, a larger proportion of HCPs in the HIV Care and Treatment Clinic thought HIV-affected couples were irresponsible in their pursuit of pregnancy without assisted reproductive services, compared with HCPs in obstetrics and gynecology $(P=0.009)$ (Fig. 1). Resident physicians were more likely than staff physicians to consider it irresponsible for HIV-affected couples to achieve pregnancy without using assisted reproductive services ( $P=0.134$ ) (Fig. 2).

Despite varying knowledge, all HCPs in the HIV Care and Treatment Clinic believed that HIV-infected individuals felt comfortable discussing their reproductive desires with their HCP. Female HCPs would be more likely than their male colleagues to refer HIV-affected couples planning a pregnancy for assisted reproductive services if cost and access barriers were removed (8/9 [89\%]) vs $2 / 5$ ([40\%]), $P=0.095)$.

\section{4 | DISCUSSION}

From the results, it is concluded that the integration of assisted reproductive services into HIV care and treatment programs is acceptable and feasible to HCPs. Formal training of HCPs could improve the implementation of assisted reproductive services in low-resource settings for HIV-affected couples.

The ability to bear children is fundamental to Ethiopian culture. As expressed by an HIV clinic provider, "In Ethiopia, once a man and a woman are married, people expect to see their first child within a year or two." Given the personal and cultural expectations, HIV-affected couples may knowingly risk HIV transmission to fulfill their reproductive goals. Therefore, it is imperative that the risk of HIV transmission in HIV-affected couples planning to achieve pregnancy be reduced through the provision of assisted reproductive services.

Despite the availability of safer reproductive methods for HIV-affected couples, their implementation in low-resource environments has been slow. The likelihood that HCPs will offer their clients assisted reproductive interventions, when available, depends on their attitudes toward their clients, the effectiveness of the technologies, and their use in the context of societal and cultural norms. In Ethiopia, the uptake of assisted reproductive interventions is limited by cost, the number of clinical sites providing services, and the availability of trained HCPs. Additionally, clients are currently requesting services in greater proportions from HCPs who reported not providing these services, such as those in the HIV Care and Treatment Clinic. 


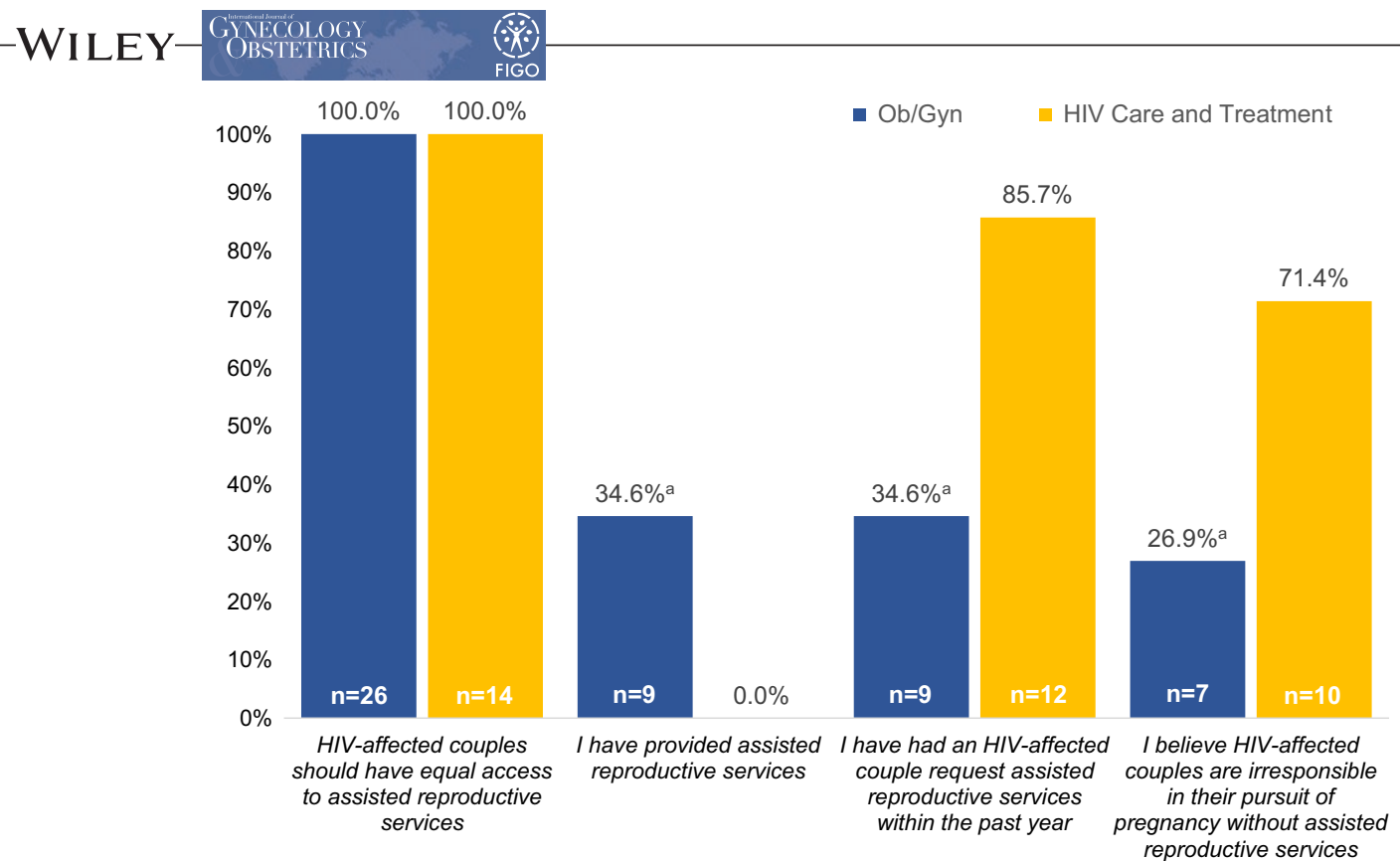

FIGURE 1 Request and provision of assisted reproductive services by clinic ( $n=40)$. Data are expressed as the proportion of "strongly agree" or "agree" responses recorded using a five-point Likert scale to the corresponding prompt. Abbreviation: Ob/Gyn, Department of Obstetrics and

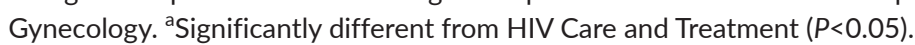

As awareness and understanding of reproduction in HIV-affected couples has increased, they could now feel enabled to achieve their reproductive goals. Previously, HIV-affected couples were stigmatized for having or desiring children, but acceptance has grown because the risk of transmitting HIV to the child has been greatly reduced by engagement in prevention of mother-to-child transmission (PMTCT) programs. The HCPs noted that if an HIV-affected woman is provided with information on antiretroviral therapy and PMTCT, she will be more likely to have a positive attitude toward having a healthy,
HIV-uninfected child. ${ }^{9}$ They also reported that HIV infection does not change reproductive desires, which are influenced by multiple factors including the number of children the woman already has, ${ }^{10}$ time since HIV diagnosis, current health status of the HIV-infected individual, ${ }^{11}$ age, and disclosure of the HIV-positive status to the sexual partner. ${ }^{12}$

As identified by the MTCT-Plus Initiative, ${ }^{13}$ a multinational study conducted in seven African countries, "Pregnancy planning and management [is] a critical but neglected component of HIV care and treatment services." A HCP indicated that "I think when you see our setup

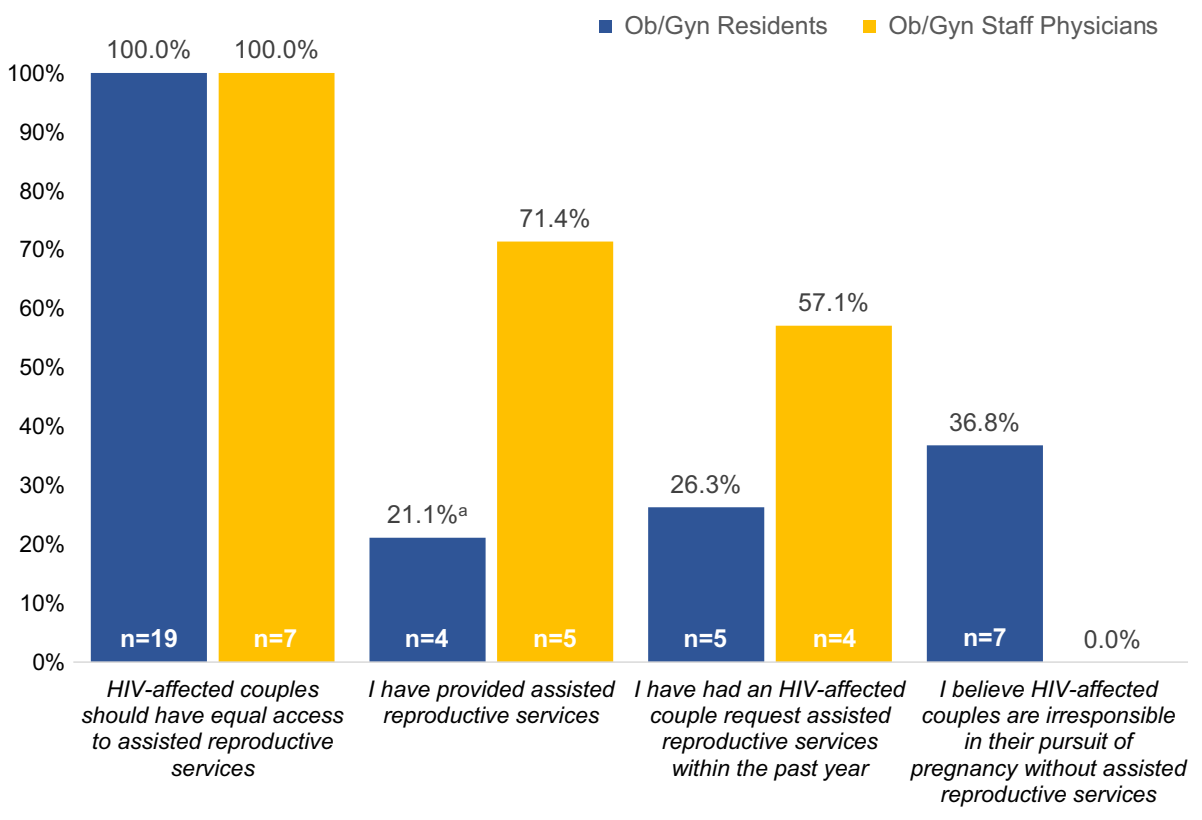

FIGURE 2 Request and provision of assisted reproductive services in Ob/Gyn by role ( $\mathrm{n}=26)$. Data are expressed as the proportion of "strongly agree" or "agree" responses recorded using a five-point Likert scale to the corresponding prompt. Abbreviation: Ob/Gyn, Department of Obstetrics and Gynecology. ${ }^{a}$ Significantly different from Ob/Gyn staff physicians $(P<0.05)$. 
TAB LE 2 Facilitators of assisted reproductive services.

\begin{tabular}{|c|c|}
\hline Description of facilitator & Quote from HCP \\
\hline \multirow[t]{2}{*}{ Childbearing is viewed as a right } & $\begin{array}{l}\text { And I know there are some of the physicians who disagree with discordant couples trying to } \\
\text { conceive. I believe that they have the right to conceive. (Female, Attending 2, aged } 30 \mathrm{y} \text { ) }\end{array}$ \\
\hline & $\begin{array}{l}\text { I have no problem with these discussions. It doesn't matter whether the patient is HIV-infected } \\
\text { or not because I do understand their desire to have kids; that's the most important thing. } \\
\text { (Female, Resident } 1 \text {, aged } 27 \mathrm{y} \text { ) }\end{array}$ \\
\hline $\begin{array}{l}\text { Fears of HIV transmission to a provider } \\
\text { during procedures have decreased with } \\
\text { increasing ART }\end{array}$ & $\begin{array}{l}\text { Yeah, nowadays things have changed. When we were students, [providers were] fearful for } \\
\text { HIV-positive individuals. But nowadays we will start them on ART... and nobody usually } \\
\text { worries about the extent of the problems and the hazard to the [HCP]. So usually we are ok } \\
\text { about advising them to have children. (Male, Resident } 1 \text {, aged } 27 \text { y) }\end{array}$ \\
\hline $\begin{array}{l}\text { The more information about HIV ART and } \\
\text { prevention of mother-to-child transmission the } \\
\text { woman has, the more likely she will be to have } \\
\text { a positive attitude toward having a healthy, } \\
\text { HIV-uninfected child }\end{array}$ & $\begin{array}{l}\text { Actually, it is difficult to change the mindset of the people in short period of time. In the } \\
\text { countryside, there are some areas where they thought that a HIV [positive] mother cannot } \\
\text { have a baby without HIV. And they discriminate the mothers in the countryside. But [in] the } \\
\text { town and in most parts of the country, they know the probability of having a baby without HIV. } \\
\text { But still there is that discrimination. (Male, Resident 1, aged } 27 \mathrm{y} \text { ) }\end{array}$ \\
\hline $\begin{array}{l}\text { Patients almost always listen to HCP instructions } \\
\text { and highly trust the word of their HCP }\end{array}$ & $\begin{array}{l}\text { Usually they don't hide from their doctors even what they hide from their husbands. In our } \\
\text { culture doctors are like God. (Male, Resident 1, aged } 29 \text { y) }\end{array}$ \\
\hline
\end{tabular}

Abbreviations: ART, antiretroviral therapy; $\mathrm{HCP}$, healthcare provider.

in our country, usually preconception care is not our strength." This lack of prenatal care is a barrier to PMTCT and assisted reproductive service implementation and delivery. The engagement of sexual partners in medical care is an additional barrier that should be addressed. The HCPs expressed that partners seldom accompany one another to medical visits, even when asked by a provider to do so. This phenomenon is especially prevalent in the context of HIV screening of partners. As expressed by one HCP, "HCPs ask the women to bring their husbands in to get tested if the woman is positive but often he does not come."

Several HCPs expressed that if a woman can achieve pregnancy without an intervention, she is more likely to select this option, because some clients may not be accepting of assisted reproductive services. This attitude comes from a place of both practicality and religion, because Ethiopia has a rich religious culture wherein the Ethiopian Orthodox and Muslim religious institutions have much influence over daily affairs. The interviews found that religious leaders, the media, and community health workers are viewed as important avenues for the distribution of accurate clinical information related to assisted reproductive services in order to increase a client's acceptance and understanding. Accurate information is necessary to alleviate the fears about using these services that were mentioned by several HCPs (for example, mislabeling of sperm during the sperm washing process, resulting in the wrong sperm being used to fertilize a woman's oocyte).

Burdens placed by the workload of HCPs must also be considered. Healthcare providers in Ethiopia have some of the highest clinical demands in the world. In 2009, the $\mathrm{WHO}^{14}$ estimated the physician density in Ethiopia at only 0.025 physicians per 1000 people. Furthermore, laboratory technicians are required for the provision of sperm washing; in 2009, there were only 0.035 laboratory health workers per 1000 individuals. ${ }^{14}$ The HCPs in the present study acknowledged that additional clinical time will be required to effectively provide counseling on assisted reproductive services. With new medical schools being established across Ethiopia, the healthcare workforce (i.e., physicians, nurses, clinical officers, and pharmacists) is predicted to increase at a rate faster than the rate of the Ethiopian population. ${ }^{15}$ Despite the possibility that HIV-affected couples may not use assisted reproductive services to achieve pregnancy, the present findings indicate that clients will still value their HCP's knowledge of these services. The overarching belief is that the provision of assisted reproductive services should be routinely available without cost to HIV-affected couples; however, this may be difficult to achieve in light of the other financial obligations of the Ministry of Health. Moreover, HCPs may be reluctant to offer assisted reproductive services to HIV-affected couples if they perceive them to be unable to afford such services.

Looking forward, HCPs recognize and accept their responsibility for providing information on assisted reproductive services to HIVaffected individuals and couples. However, there is limited knowledge of these services among HCPs. Education on assisted reproductive services is necessary in undergraduate medical training for physicians, nurses, clinical officers, and pharmacists. Therefore, a training curriculum should be developed, evaluated, and implemented in medical education, and subsequently integrated into HIV care and treatment services. It is our hope that HCPs will begin to routinely assess the reproductive desires of HIV-affected individuals and couples presenting in their care with the following question: "Do you hope to have a child in the near future?" in order to begin the dialogue that may prevent new HIV infections and result in a healthy pregnancy, even if they are not the ones to provide the service.

In the future, a larger sample size and the inclusion of multiple health centers throughout the country may allow for generalizable, in-depth conclusions to be made. Evaluating the perspective of additional HCPs throughout regions of Ethiopia may enhance the generalizability of the present study findings.

The present study identified existing structural, personal, and cultural barriers that could impede the implementation and uptake of assisted reproductive services for HIV-affected couples planning to achieve a pregnancy. Addressing these barriers may help advance 
TABLE 3 Barriers to assisted reproductive services.

\begin{tabular}{|c|c|}
\hline Description of barrier & Quote from HCP \\
\hline Clinical setup & $\begin{array}{l}\text { For example, having one room, a separate room with a door where we and the patient can have privacy } \\
\text { and you can discuss with them and you can show them how it is going to be done. So, just preparing a } \\
\text { private room and having the training to counsel them. (Female, Resident } 1 \text {, aged } 27 \text { y) }\end{array}$ \\
\hline Patient load & $\begin{array}{l}\text { Usually, I would be very busy. There are four residents and so each has to see around } 20 \text { patients. So } \\
\text { that is going to be very busy but usually for these targeted individuals, usually four per week, you can } \\
\text { manage time for these individuals, I think. (Male, Resident } 1 \text {, aged } 27 \text { y) }\end{array}$ \\
\hline $\begin{array}{l}\text { Assisted reproductive services cannot be } \\
\text { offered unless HIV infection is } \\
\text { suspected/known }\end{array}$ & $\begin{array}{l}\text { Most of the time you catch them after they have the baby [or] most of the time they are pregnant } \\
\text { while they are diagnosed [with HIV]. (Male, Resident 1, aged } 28 \mathrm{y} \text { ) }\end{array}$ \\
\hline Involvement of male partner & $\begin{array}{l}\text { For the male partner if they are found to be HIV-positive, it is less likely to be counseled and bring the } \\
\text { female to being tested. There is no universal way of testing male patients. There is no such policy. In } \\
\text { some hospitals, all patients who come for other service are offered to have HIV test. Then at that time } \\
\text { they are counseled to bring their partner. (Male, Attending } 2 \text {, aged } 36 \text { y) }\end{array}$ \\
\hline $\begin{array}{l}\text { Patients are willing to travel/pay for } \\
\text { services but it places a huge burden on } \\
\text { themselves and their families }\end{array}$ & $\begin{array}{l}\text { As far as I feel, these methods are very expensive. As the patients are poor they may not afford that. If } \\
\text { they try to afford it, it will compromise most of their life. They sold all their cattle and they came and } \\
\text { didn't have anything and they go and die of hunger. It is difficult for patients. So, if the government or } \\
\text { other NGO give them some subsidization of the cost it will be easy. (Male, Resident } 1 \text {, aged } 29 \text { y) }\end{array}$ \\
\hline $\begin{array}{l}\text { Some HCPs purposefully do not offer } \\
\text { assisted reproductive services to } \\
\text { patients they know are unable to } \\
\text { afford it }\end{array}$ & $\begin{array}{l}\text { Yeah, since we know most of our clients, their economic background, and so on, we don't usually offer } \\
\text { for them. But if they ask, we offer. (Male, Resident 1, aged } 30 \mathrm{y} \text { ) }\end{array}$ \\
\hline
\end{tabular}

If they cannot afford I will not advise them. (Male, Resident 1, aged 27 y)

Cost of assisted reproductive services

The government has donations for the ART drugs and the HIV services. So if this program is incorporated within HIV service, I am sure they will be willing to pay. It is not the government who is paying from their pocket, it is the donors. So the ultimate goal for HIV is prevention of transmission to any person whether it is to the man or to the woman or to the child. One way or another this affects the outcome significantly. It has to be incorporated to the HIV clinic. The service has to be given just like any other service. (Female, Attending 2, aged 30 y)

I can't guess the cost, how much it takes. If it is supplemented at least at the beginning so that the service will be known by people at least for a time, after a while everybody knows about it ... [until] we reach that stage it should either be free or supplemented by the government or by the service provider ... Then we can set a fair price and based on the financial capacity of the population. (Male, Attending 2, aged $37 \mathrm{y}$ )

HCPs as providers of assisted reproductive services, education, and counseling

Community engagement
I think the physician has a duty [to] initiate these conversations because the patient has no information regarding the risk of transmission and the subsequent regret and the psychological impacts after getting pregnant. She has no knowledge. So, the physician also is responsible regarding this issue. (Male, Resident 1, aged $27 \mathrm{y}$ )

If the church accepts it the people will accept it. (Male, Attending 2, aged $36 \mathrm{y}$ )

Individuals in the rural [areas], like priests or public figures, if you use [them] and the mass media, I think you can change. The way should first be created by the physician and the others. (Male, Resident 1, aged 28 y)

These health extension workers are originally from their own community. And they have good attachment with the community. They would be accepted rather than somebody coming from Addis or Dire Dawa. (Male, Resident 1, aged 29 y)

The society wants [to] think [about it] in natural way, which is given from God. Having it another way is [sometimes] not accepted. Peoples are not understanding this method. They put it as ... they couldn't believe that it is his and her egg and they couldn't understand this thing, [that it is] a matter of

replacement. (Female, Resident 1 , aged 28 y)
If women can get pregnant naturally, they may not accept the use of reproductive technology

Abbreviations: ART, antiretroviral therapy; HCP, healthcare provider; NGO, nongovernmental organization.

HIV prevention efforts in communities where the burden of infection is high. The present study findings may impact the implementation and delivery of assisted reproductive services for HIV-affected couples in Ethiopia and other low-resource environments in SubSaharan Africa. The successful introduction of assisted reproductive services into HIV care and treatment programs will require
HCP education and training, and access to reproductive counseling must extend into community health clinics in urban and rural areas. Clinical barriers to HIV-affected couples being able to access options for achieving pregnancy should be addressed with effective healthcare policies to optimize the implementation of assisted reproductive services. 


\section{AUTHOR CONTRIBUTIONS}

ANP contributed to performing the in-depth interviews, the quantitative data analysis, and manuscript writing. KS contributed to performing the in-depth interviews, the quantitative data analysis, and manuscript writing. HMB contributed to the qualitative data analysis and manuscript revisions. BM contributed to performing the in-depth interviews and manuscript revisions. DB contributed to performing the in-depth interviews and manuscript revisions. EK contributed to the quantitative data analysis and manuscript revisions. LTG contributed to performing the in-depth interviews and manuscript revisions. OM contributed to the conception of the study, the qualitative data analysis, and manuscript writing.

\section{ACKNOWLEDGMENTS}

The present study project was supported in part by the African Studies Center, the Institute for Research on Women and Gender, and the Department of Obstetrics and Gynecology, all of the University of Michigan, Ann Arbor, MI, USA. The authors would like to acknowledge Drs. Ferid Abbas and Senait Fisseha for their contributions and collaborative engagement for the development and conduct of the present study, and Ms. Sarah Block for her editorial and graphic design expertise.

\section{CONFLICTS OF INTEREST}

The authors have no conflicts of interest.

\section{REFERENCES}

1. Federal Ministry of Health Ethiopia: Health and Health Related Indicators. Addis Ababa: FMoHE [Center for National Health Development in Ethiopia Website]. 2012. http://www.cnhde.org. et/wp-content/uploads/2013/04/Health\%20and\%20Health\%20 Related\%20Indicators\%202005\%20E.C.pdf. Accessed March 1, 2017.

2. Chan $\mathrm{KCW}$, Wong $\mathrm{KH}$, Lee SS. Universal decline in mortality in patients with advanced HIV-1 disease in various demographic subpopulations after the introduction of HAART in Hong Kong, from 1993 to 2002. HIV Med. 2006;7:186-192.
3. Getachew M, Alemseged F, Abera M, Deribew A. Factors affecting fertility decisions of married men and women living with HIV in South Wollo Zone, Northeast Ethiopia. Ethiop J Health Dev. 2010;24: 214-220.

4. Asfaw HM, Gashe FE. Fertility intentions among HIV positive women aged 18-49 years in Addis Ababa Ethiopia: A cross sectional study. Reprod Health. 2014;11:36.

5. Spino A, Clark M, Stash S. HIV Prevention for Serodiscordant Couples. USAID and AIDS Support and Technical Assistant Resources, AIDSTAR-One Task Order I [USAID website]. 2010. http://pdf.usaid. gov/pdf_docs/Pnadx303.pdf. Accessed March 3, 2017.

6. Brubaker SG, Bukusi EA, Odoyo J, Achando J, Okumu A, Cohen CR. Pregnancy and HIV Transmission among HIV-discordant couples in a clinical trial in Kisumu, Kenya. HIV Med. 2010;12:316-321.

7. Demissie DB, Tebeje B, Tesfaye T. Fertility desire and associated factors among people living with HIV attending antiretroviral therapy clinic in Ethiopia. BMC Pregnancy Childbirth. 2014;14:1-10.

8. Savasi V, Ferrazzi E, Lanzani C, Oneta M, Parrilla B, Persico T. Safety of sperm washing and ART outcome in 741 HIV-1-serodiscordant couples. Hum Reprod. 2007;22:772-777.

9. Deressa W, Seme A, Asefa A, Teshome G, Enqusellassie F. Utilization of PMTCT services and associated factors among pregnant women attending antenatal clinics in Addis Ababa, Ethiopia. BMC Pregnancy Childbirth. 2014;14:328.

10. Myer L, Morroni C, Rebe K. Prevalence and determinants of fertility intentions of HIV-infected women and men receiving antiretroviral therapy in South Africa. AIDS Patient Care STDS. 2007;21: 278-285

11. Chen JL, Phillips KA, Kanouse DE, Collins RL, Miu A. Fertility desires and intentions of HIV-positive men and women. Fam Plann Perspect. 2001;33:144-153.

12. Melaku YA, Zeleke EG, Kinsman J, Abraha AK. Fertility desire among HIV-positive women in Tigray region, Ethiopia: Implications for the provision of reproductive health and prevention of motherto-child HIV transmission services. BMC Womens Health. 2014; 14:137.

13. Myer L, Carter RJ, Katyal M, Toro P, El-Sadr WM, Abrams EJ. Impact of antiretroviral therapy on incidence of pregnancy among HIV-infected women in Sub-Saharan Africa: A cohort study. PLoS Med. 2010; 7:e1000229.

14. World Health Organization. Global Health Observatory Data of Healthcare Workforce [WHO website]. 2009. http://apps.who.int/ gho/data/node.main.A1444. Accessed March 6, 2017.

15. Kinfu Y, Dal Poz MR, Mercer H, Evans DB. The health worker shortage in Africa: Are enough physicians and nurses being trained? Bull World Health Organ. 2009;87:225-230. 